\title{
Orthopaedic manifestations of neurofibromatosis type 1: A case report
}

\author{
FLORENTINA NĂSTASE $^{1 *}$, DIANA SABINA RADASCHIN ${ }^{2,3}$, ELENA NICULEȚ $^{4-6}$, \\ ANDREI VLAD BRĂDEANU ${ }^{4}$, MĂDĂLINA CODRUT,A VERENCA ${ }^{1}$, AUREL NECHITA $^{7}$, VALENTIN CHIONCEL $^{8,9}$, \\ LAWRENCE CHUKWUDI NWABUDIKE ${ }^{10}$, LILIANA BAROIU ${ }^{2,11^{*}}$, EDUARD DRIMA POLEA ${ }^{2}$, \\ SILVIA FOTEA ${ }^{2,6^{*}}$, LUCRETIA ANGHEL ${ }^{2,12}$, ALEXANDRU NECHIFOR ${ }^{2}$ and ALIN LAURENŢIU TATU A $^{2,3,6,13}$ \\ ${ }^{1}$ Department of Neuropsychomotor Rehabilitation, 'Sf. Ioan' Clinical Hospital for Children, \\ 800487 Galati; ${ }^{2}$ Clinical Medical Department, Faculty of Medicine and Pharmacy, \\ ${ }^{3}$ Research Center in The Field of Medical and Pharmaceutical Sciences, \\ ${ }^{4}$ Department of Morphological and Functional Sciences, Faculty of Medicine and Pharmacy, \\ 'Dunarea de Jos' University, 800010 Galati; ${ }^{5}$ Department of Pathology, 'Sf. Apostol Andrei' Emergency Clinical Hospital, \\ 800578 Galati; ${ }^{6}$ Multidisciplinary Integrated Center of Dermatological Interface Research MIC-DIR, 'Dunarea de Jos' \\ University, 800010 Galati; 7 Department of Pediatrics, 'Sf. Ioan' Clinical Hospital for Children, 800487 Galati; \\ ${ }^{8}$ Cardio-thoracic Department, 'Carol Davila' University of Medicine and Pharmacy, 020021 Bucharest; \\ ${ }^{9}$ Clinical Cardiology Department, 'Bagdasar Arseni’ Emergency Hospital, 041915 Bucharest; \\ ${ }^{10}$ Department of Diabetic Foot Care, 'N. Paulescu' National Institute of Diabetes, 011233 Bucharest; \\ ${ }^{11}$ First Infectious Diseases Department, 'Sf. Cuvioasa Parascheva' Clinical Hospital of Infectious Diseases, \\ 800179 Galati; ${ }^{12}$ Internal Medicine Department, 'Sf Andrei’ Clinical Emergency Hospital, 800578 Galati; \\ ${ }^{13}$ Dermatology Department, 'Sf. Cuvioasa Parascheva' Clinical Hospital of Infectious Diseases, 800179 Galati, Romania
}

Received August 9, 2021; Accepted September 8, 2021

DOI: $10.3892 / \mathrm{etm} .2021 .11058$

\begin{abstract}
Neurofibromatosistype 1(NF1) or von Recklinghausen disease is one of the most common autosomal dominant genetic diseases. It is characterized by 'café-au-lait' spots and multiple tumors starting from the central and peripheric nervous system. The diagnosis is determined on two out of seven criteria: i) A total of 6 or more light brown spots larger than $5 \mathrm{~mm}$ in diameter (pre-puberty) or $15 \mathrm{~mm}$ in diameter (post-puberty); ii) a total of 2 or more neurofibromas or one plexiform neurofibroma; iii) axillary or inguinal freckling; iv) optic glioma; v) a total of 2 or more Lisch nodules; vi) bone abnormalities: tibia pseudarthrosis or dysplasia of the sphenoid wing; and vii) a relative of first degree having an NF1 diagnosis. A total of
\end{abstract}

Correspondence to: Dr Elena Niculeț or Dr Andrei Vlad Brădeanu, Department of Morphological and Functional Sciences, Faculty of Medicine and Pharmacy, 'Dunarea de Jos' University, 35 Al. I. Cuza Street, 800010 Galati, Romania

E-mail: helena_badiu@yahoo.com

E-mail: bradeanu.andreivlad@yahoo.com

${ }^{*}$ Contributed equally

Key words: orthopaedic manifestations, neurofibromatosis type 1, von Recklinghausen disease, café-au-lait spots, pseudarthrosis $\sim 50 \%$ of patients have significant musculoskeletal manifestation, with scoliosis and congenital pseudarthrosis of tibia most common. Management of the orthopaedic manifestations of NF1 is often difficult. Due to NF1 influencing multiple organ systems, patients are likely to benefit most from a multidisciplinary treatment strategy.

\section{Introduction}

Neurofibromatosis type 1 (NF1) was first described in the 13th century in the literature by Madigan, Schaw and Masello in 'Neurofibromatosis in the 13th century and report of NF-like case-Monstrorum History', but there are descriptions of individuals presumed of having neurofibromatosis, recovered in manuscripts from 1,000 B.C. However, only in 1882 was it recognized by the German pathologist Freidrich von Recklinghausen as a distinct disorder and he initiated the term 'neurofibroma', as he observed the appearance of tumors from the sheath of the peripheral nerve (1-5). NF1 is a multisystem, autosomal dominant genetically transmitted disease, also known as von Recklinghausen disease, which influences the cell growth of neuronal tissues. NF1 is an inherited disorder relatively common, family history being present in half of the cases, the rest developing a new genetic mutation, and it affects 1 in 2,500-3,000 births worldwide, regardless of sex and ethnicity (6-12).

Neurofibromin 1, the gene of NF1, was first discovered in 1990 located on chromosome 17, band q11.2 and is a 
large gene which codes the protein neurofibromin, with the highest rates of spontaneous mutations in the entire human genome $(2,3,5,13-18)$. Neurofibromin is omnipresent during development in human tissue and later is identified exclusively in the nervous system, neurons, Schwann and glial cells in high concentrations $(1,3,15,19)$. NF1 genetic testing is reserved for making reproductive decisions or for unusual forms of disease, the diagnosis finally being made based on clinical criteria $(4,20)$.

The patients with clinical manifestations can be diagnosed by performing a careful examination. The signs may be dermatologic/cutaneous: café-au-lait spots/macules (CALM), axillary freckling; ocular: Lisch nodules, optic nerve glioma; endocrine: precocious/delayed puberty; neurologic: brain tumors, epilepsy, headache, macrocephaly, mental retardation, learning disabilities; cardiovascular: vascular defects, hypertension; orthopaedic: pseudarthrosis, scoliosis, pectus excavatum, genu valgum/varum. Each category can have variable severity $(3,18,21)$. For the diagnosis of NF1, 7 cardinal diagnostic criteria (Table I) have been delineated, taking into consideration the most common cutaneous, neurologic, ocular and skeletal manifestations with the addition of the genetic component, and at least 2 of the listed features The diagnostic criteria were defined in 1988 during the Neurofibromatosis Conference Statement of the National Institutes of Health Consensus Development Conference, in Bethesda, MD, USA $(1,3,12,18,20)$. Diagnosis can be delayed due to signs/symptoms that appear at variable ages and due to the patient having some dermatologic features but without meeting enough diagnostic criteria $(1,3)$.

Café-au-lait spots are the most common and among the silent features of NF1. They are present in $99 \%$ of patients at birth or appear in the first two years of life, with multiple spots being very suggestive for NF1. The spots are flat brownish macules, uniform colored from tan to dark brown, 10-100 mm in diameter, ovoid shape, with well-defined borders. These lesions tend to darken with sun exposure, lighten with age and have non-malignant potential $(12,17,22,23)$. The spots with the same characteristics but smaller in diameter are named freckles or ephelides and are localized inguinal or, more common, in axillary zones (Crowe sign), in almost $80 \%$ of the children starting at 3-5 years old, following the appearance of café-au-lait spots $(3,4,12,18)$. Neurofibromas are benign tumors composed by neoplastic Schwann cells, mast cells, endothelial cells, macrophages, located along the nerves, with an accelerated proliferation during puberty and pregnancy. The types of neurofibromas are: cutaneous (superficial); subcutaneous (deeper); nodular plexiform; and diffuse plexiform neurofibromas that penetrate deep into bones, muscle and viscera. They usually become apparent after puberty and increase in size and number continuously during adulthood and they should be differentiated from other skin lesions $(3-5,12,24,25)$. In addition to neurofibromas, neurofibromatosis may be associated with other tumors of the central nervous system including glioma of the optic nerve, hamartoma of the iris, meningioma, and glioblastoma $(4,12)$. Neurofibrosarcomas, malignant peripheral nerve sheath tumors (MPNSTs), are a severe complication with an elusive nature and high rate of recurrence $(3,5,26)$.

The cardiovascular abnormalities developed in NF1 include congenital heart disease; vasculopathy (aortic coarctation), renal and cerebral artery stenosis, arteriovenous malformations; as well as, pulmonary hypertension which may be a rare, but formidable complication of NF1 $(4,5,27)$. NF1 patients often present with hypertension due to renal artery stenosis or in association with pheochromocytoma or paragangliomas (28). The neurological manifestations associated with the disease are macrocephaly without hydrocephalus, mild epilepsy, cognitive problems with a low average IQ, and learning difficulties. Behavioral problems include impaired socialization, sleep disturbance, anxiety and depression $(4,5,12)$. Other associated autoimmune diseases have been previously described as uncommon occurrences, such as lichen sclerosus or vitiligo (29-34).

\section{Case report}

A 16 year-old boy living in a rural area was admitted on July 2016 to the clinical Department of Neuropsychomotor Rehabilitation, 'Sf.Ioan' Clinical Hospital for Children (Galati, Romania) for clinico-functional evaluation and specific treatment. The family history revealed the mother and two maternal uncles with NF1 skin markers which were uninvestigated and undiagnosed, as well as a sister and a brother diagnosed with NF1. From his personal history it was recorded that the patient had undergone 3 febrile seizures until the age of 3 for which he had not received treatment, and café-au-lait spots that appeared after the age of 2 . At the age of 5 years the patient was hospitalized with the diagnosis of NF1-associated congenital pseudarthrosis in both left leg bones and the surgical treatment of pseudarthrosis, osteosynthesis with Steinmann brooch and Ilizarov external fixative implant (removed after one year) were performed. At the age of 7 years the patient received surgical treatment for pseudarthrosis again by Phemister procedure. Fig. 1 reveals the anterior and the lateral view of the radiological images of the left leg of the patient obtained at age of 10 , that reveal an old fracture 1/3 lower of the left tibial shaft strengthened by osteosynthesis, lack of bone lower extremity left fibula, and intense changes in osteoporosis in both left leg bones.

From the clinical examination the following were observed: i) a weight of $49 \mathrm{~kg}$ and a height of $154 \mathrm{~cm}$; ii) autonomous walking, limping on the left; iii) spinal deviation in the frontal plane to the right (dorsal) and to the left (lumbar); iv) humeral imbalance, with the left shoulder ascended; v) the waist triangle erased on the left (Fig. 2A); vi) sternal depression in the lower $1 / 3$ and flared ribs (Fig. 2B); vii) normal spine mobility; viii) multiple café-au-lait spots (over 6 in number), the largest on the left flank, with a diameter of $3.5 / 3 \mathrm{~cm}$ (Fig. 3A); iv) axillary freckles (Fig. 3B); $\mathrm{x})$ two surgical scars present on the left pretibial area, one measuring $13 \mathrm{~cm}$, and the other $4 \mathrm{~cm}$, respectively; xi) left genum valgum; xii) lower limb inequality, left leg shorter by $5 \mathrm{~cm}$; xiii) left hypotrophy on the leg $(3 \mathrm{~cm})$ and on the thigh (2 cm) (Fig. 4); xiv) macrocephaly; xv) language disorder; and $x v i$ ) mild intellectual deficit.

\section{Discussion}

NF1 is a multisystem, autosomal dominant genetically transmitted disease, which influences the cell growth of neuronal 
Table I. Diagnostic criteria for neurofibromatosis type 1.

Characteristics

Criteria

1. Six or more café-au-lait macules

$5 \mathrm{~mm}$ in diameter prepubertal $15 \mathrm{~mm}$ in diameter postpubertal

2. Two or more neurofibromas or one plexiform neurofibroma Of any type

3. Freckling

4. Optic nerve glioma

5. Two or more Lisch nodules (iris hamartomas)

6. A bone lesion

7. A first-degree relative with NF1
Axillary

Inguinal (Crowe sign)

Identified by an ophthalmologist through slit-lamp examination Sphenoid wing dysplasia

Typical long bone abnormalities -

Pseudarthrosis/thinning of cortex

Parent

Sibling

Offspring
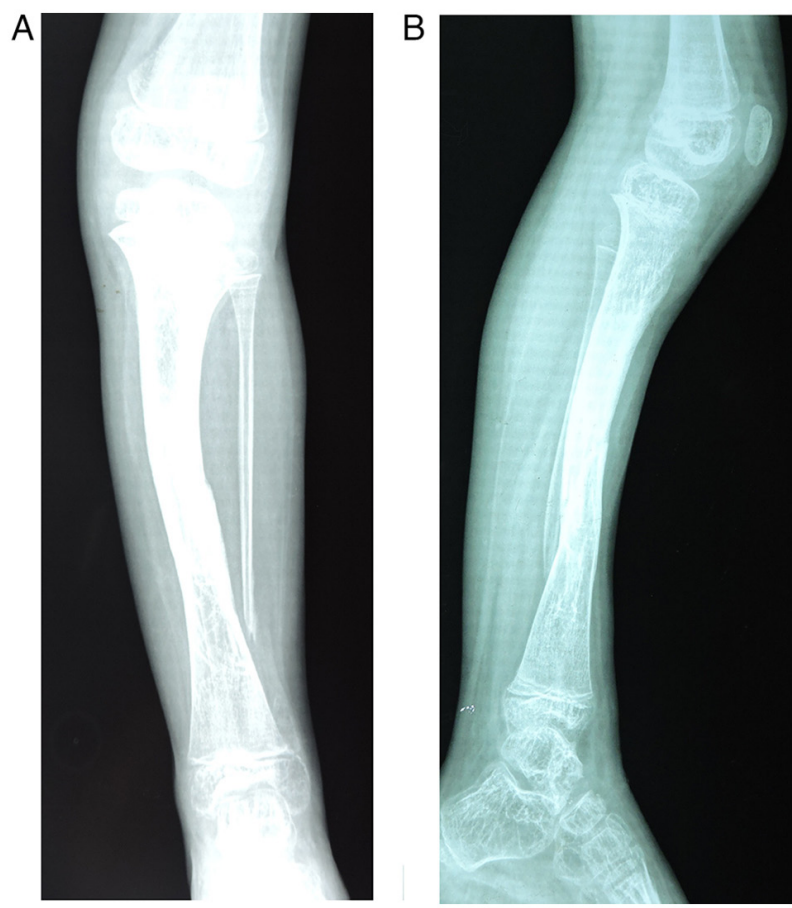

Figure 1. (A) Anterior and (B) lateral view of the radiological images of the left leg.

tissues. NF1 is an inherited disorder relatively common, with family history being present in half of the cases, while the remaining cases develop a new genetic mutation, and it influences 1 in 2,500-3,000 births worldwide (6-12). The patients with clinical manifestations can be diagnosed by performing a careful examination. The signs may be cutaneous, ocular, endocrine, neurologic, cardiovascular, and orthopaedic: pseudarthrosis, scoliosis, pectus excavatum, genu valgum/varum $(3,18,21)$.

The skeletal manifestations of von Recklinghausen disease (NF1) can be generalized, most commonly, and with mild clinical implications such as osteopenia or osteoporosis, or short stature; and can also be focal, less commonly, with significant morbidity, such as scoliosis, long bone dysplasia, and sphenoid
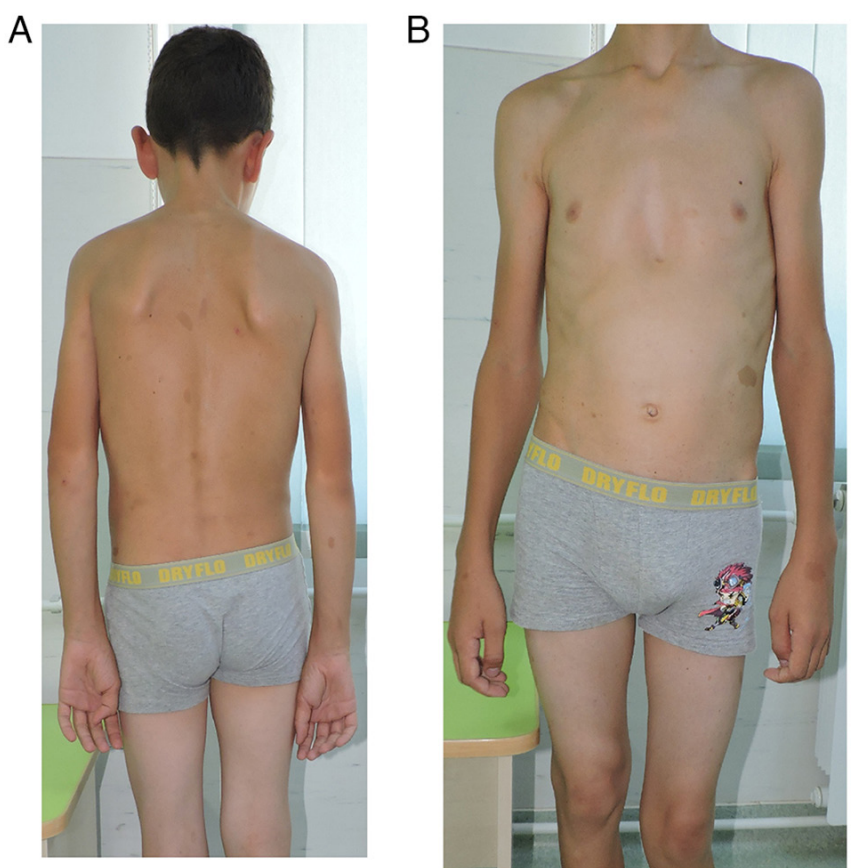

Figure 2. Clinical aspect of the thorax. (A) Posterior view and (B) anterior view.

wing dysplasia. The most frequent bones manifestations of patients with NF1 are listed in Table II.

Only 2-4\% of patients with NF1 develop long bone dysplasia, tibia being more often involved than other long bones, which are less affected (5,35-37). Congenital tibial dysplasia, also known as congenital pseudarthrosis of the tibia (CPT), is unusual in the general population, but is more common in individuals with NF1 (37-39). CPT present in NF1 is described as the antero-lateral bowing of tibia that appear at birth or in the first year of life $(40,41)$. Histopathological analysis of the resected tissue of the pseudarthrosis revealed a hard whitish fibrous tissue, surrounded by fatty lobules. Specifically between the bone ends, thick bands of dense fibrous tissue intervene, that prevent the union and constitute a true focus of pseudarthrosis, which is not a neurofibroma, but an unspecified 
Table II. Frequent bone manifestations of patients with neurofibromatosis type 1 .

\begin{tabular}{ll}
\hline Bone manifestations & \multicolumn{1}{c}{ Types } \\
\hline Bone deformities & Long bone dysplasia \\
& Congenital bone bowing \\
& Pseudarthrosis \\
& Genu varum/algum \\
& Sphenoid wing dysplasia \\
& Scoliosis \\
& Kyphoscoliosis \\
& Spondylolisthesis \\
& Cervical spine disorders \\
& Abnormalities of the rib cage \\
& Macrocephaly \\
& Short stature \\
Osteopenia \\
Osteoporosis \\
Impaired bone healing \\
Hypophosphatic rickets
\end{tabular}
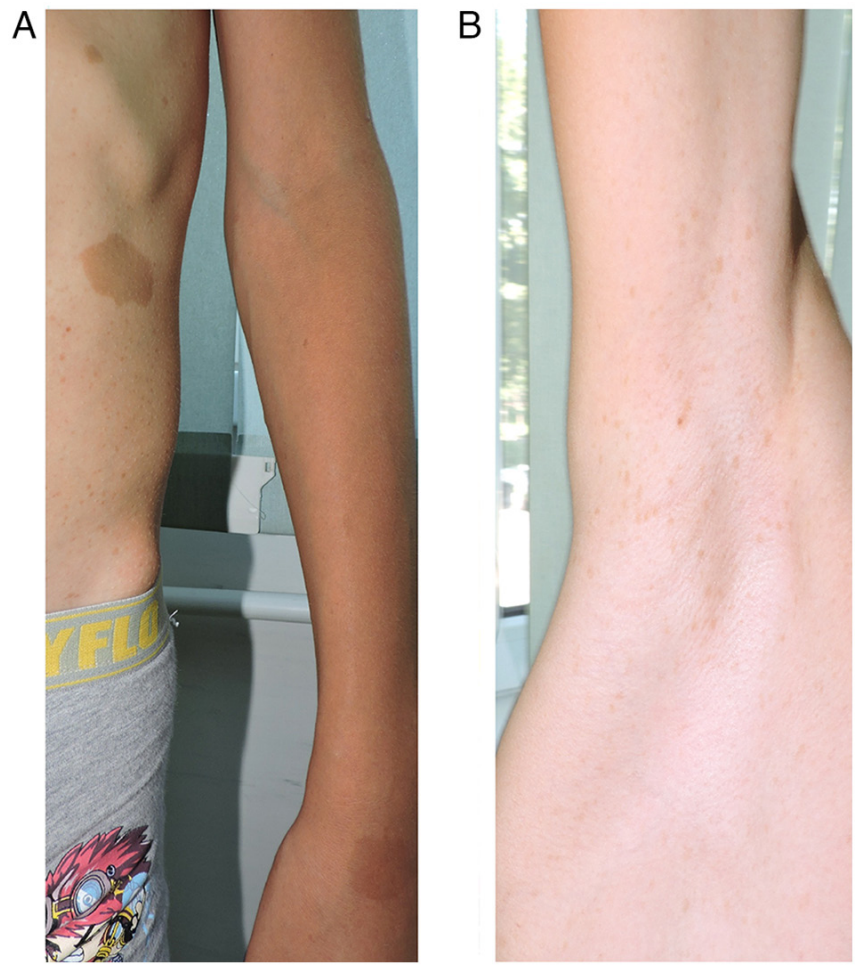

Figure 3. (A) Largest café-au-lait spot observed on the left flank, and (B) axillary freckles.

cell fibrous overgrowth $(36,42)$. Clinically, there is a varus with anterior bowing mid-distal third of the leg, with a thin, sclerotic and fragile bone, producing a spontaneous fracture of tibia or both leg bones intrauterine, perinatally or in the first years of life due to functional stress or microtrauma $(5,43)$. Once the fracture has occurred, the absence of union through the formation of the callus is characteristic. Therefore, this

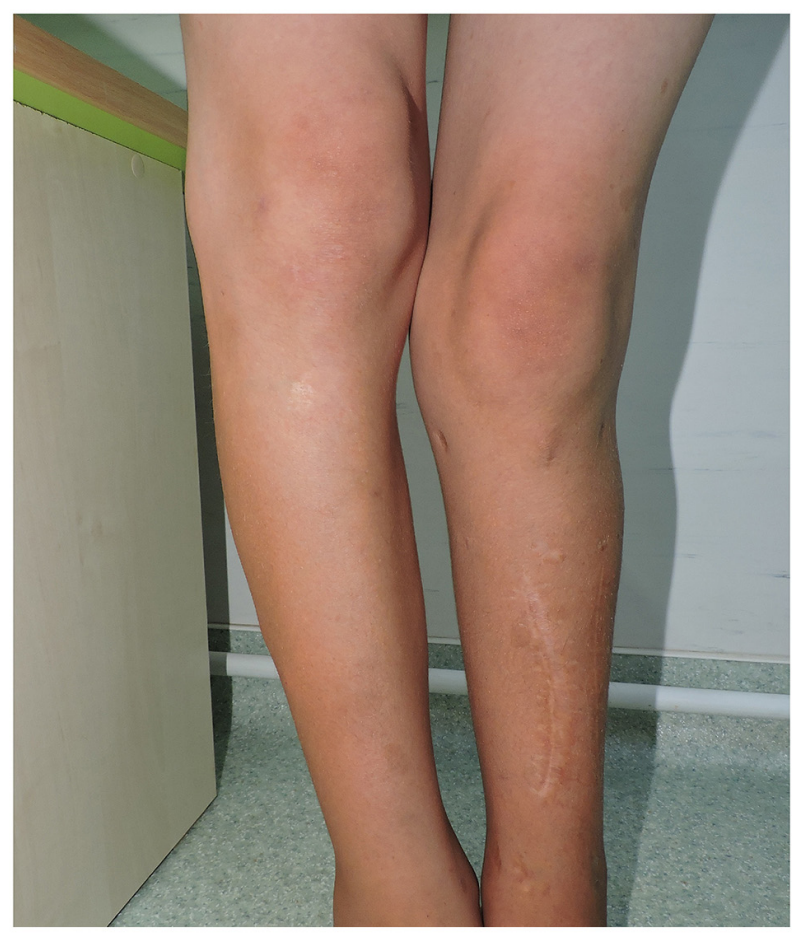

Figure 4. Clinical aspect of the both legs.

usually progresses to pseudarthrosis when a spontaneous fracture occurs in children under 4 years of age, with tibial bowing and not exhibiting adequate bony callus with treatment (44). Due to the rigid immobilization during treatment, stiffness of the ankle is frequently observed $(44,45)$. The gait and the muscular strength of the patients are altered. Early appearance followed by early surgical treatment, frequently requiring fixation of the ankle, leads to an abnormal gait $(46,47)$. The deformity with anterior bowing is usual, as well as its progressive increase with the consequent shortening of the posterior myotendinous structures of the leg and ankle $(44,48)$.

Several classifications have been proposed, considering the morphology of the lesion, but with limited prognostic value due to the changes that arise during the disease $(49,50)$. The most determining factor is the moment when the fracture appears: after 4 years of age suggests a more benign behavior, while before 4 years of age entails a more rebellious evolution $(44,45,48,51)$. The management of congenital dysplasia of the tibia associated with NF1 may be frustrating, with frequent and severe complications, fractures and refractures, common after different treatments. Surgical treatment performed without adequate biomechanical criteria does not appear to be particularly successful $(45,46,51-53)$. A non-surgical method consists of bracing with an ankle-foot or knee-ankle-foot orthosis, with the first method used until weight bearing begins, switching after that to a knee-ankle-foot method. Bracing is used to prevent fractures in dysplastic bones and if the fracture occurs to delay surgical intervention $(3,53)$. The objective of surgical treatment is to maximize the union through the resection head, following the specific methods: external fixation (Ilizarov technique), bone grafting with intramedullary fixation, and free vascularized fibular grafting. When multiple attempts have failed, and with the leg remaining extremely short, amputation may 
be the best solution $(3,5,50,53)$. Intramedullary fixation with the iliac bone, while leaving the device in place, even after healing of the fracture, is considered the first line treatment since it is a relatively easy procedure, provides stable fixation, has minimal postoperative complications and reduces the risk of refracture, compared with alternative procedures $(3,54)$. The most severe complications are residual angular deformity, limb length inequality, refracture, ankle stiffness and chronic pain (53).

The Ilizarov external fixative implant provides numerous advantages in the treatment of congenital dysplasia of the tibia and its associated problems. This method allows the surgeon to manage limb dismetria, angular deformity, proximal migration and nonunion of the fibula, ankle valgus and foot contractures (55). Refractures are extremely common, although this method initially produces a high binding rate. Another disadvantage of the Ilizarov method is the external device, which is not well tolerated by pediatric patients. The multiple complications with this procedure include dorsiflexion contracture of the ankle with calcaneo-valgus deformity, joint stiffness, cystic bone lesions, nail infections, cartilage necrosis, injury to a nerve and possible appearance of compartment syndromes (56).

The scoliosis associated with NF1 can be dystrophic, less common and more severe, with rapid progression, and non-dystrophic, with the same rate and a similar clinical appearance, but an earlier onset and poorer prognosis. Early scoliosis screening is required for patients with neurofibromatosis. After diagnosis all individuals should be MRI/CT scan-evaluated to assess the deformity and the dystrophic changes, if present, and to detect the intra/extraspinal neoplasia $(3,57)$. Dystrophic scoliosis leads to severe curves, 4-6 sharply angulated vertebra, accompanied by osseous abnormalities $(3,5,58)$. The management of nondystrophic scoliosis depends on the degree of curvature. For curves $<20^{\circ}$ the observation is enough, for curves between $20-40^{\circ}$ or for documented progression, bracing is recommended, for $>40^{\circ}$ posterior fusion is recommended, and finally for curves $>90^{\circ}$ anterior-posterior fusion is recommended $(3,59)$. In the early forms of the disease, other pathologies in differential diagnosis such as multiple symmetrical lipomatosis or diabetes and its comorbidities, may also be considered $(60,61)$.

In conclusion, NF1 (von Recklinghausen disease) influences multiple organs and the diagnosis could be made clinically, based on careful multidisciplinary examination. While certain characteristics are present at birth, others are age-related, and all of them require periodical monitoring. Other examinations (histopathologic, radiological, MRI, ophthalmologic and neurologic) are important for tracking the complications and the evolution of this disorder. The bones are affected more often in NF1, having an increased morbidity and even profound invalidism. A careful strategy for the management of musculoskeletal disabilities may improve the quality of life of patients with this disorder.

In the present study, the case of a 16 year-old male living in a rural area was presented, who at 5 years of age was diagnosed with NF1-associated congenital pseudarthrosis in both left leg bones and received the surgical treatment for pseudarthrosis, osteosynthesis with Steinmann brooch and Ilizarov external fixative implant. At the age of 7 years the patient received surgical treatment again for pseudarthrosis by Phemister procedure.

The patients with NF1 develop multiple complications, since it affects multiple systems and benefit most from a multidisciplinary strategy. If the musculoskeletal disabilities are carefully managed, the quality of life in individuals with NF1 can be improved.

The case presented was associated with frequent complications including pseudarthrosis of both bones of the leg, kyphoscoliosis, chest deformities, macrocephaly, language disorder and mild intellectual deficit. Tibial dysplasia with pseudarthrosis is a challenging complication, since the patient, after all the surgical interventions, still has a marked functional disability.

Despite advances of continuous research for the diagnosis and monitoring of NF1, there is no medical treatment available for it. Medical care should be focused on genetic counseling and the early detection of complications.

\section{Acknowledgements}

Not applicable.

\section{Funding}

The present work was supported by the 'Dunarea de Jos' University of Galati, Romania, through the research center, Multidisciplinary Integrated Center of Dermatological Interface Research MIC-DIR [Centrul Integrat Multidisciplinar de Cercetare de Interfata Dermatologica (CIM-CID)].

\section{Availability of data and materials}

The information generated and analyzed during the current study is available from the corresponding author on reasonable request.

\section{Authors' contributions}

FN and ALT were major contributors in writing the manuscript. FN, DSR, EN, ALT, AVB, MCV, SF and LB were involved in all the stages of the study. DSR, AIN, AVB, VC, AL, LCN and EN contributed to the conception and design of the work, as well as the revision of the study. AVB, AuN, VC, LCN, EDP, SF and LB helped analyze the data for the work. AVB, MCV, LA and EDP revised it for important intellectual content. ALT and AIN approved the final version to be published. FN and AVB confirm the authenticity of all the raw data. All authors have participated equally and have equal rights to this study. All authors read and approved the final manuscript and agree to be accountable for all aspects of the work in ensuring that questions related to the accuracy or integrity of any part of the work are appropriately investigated and resolved.

\section{Ethics approval and consent to participate}

Ethical approval was obtained from the Ethics Committee of the Emergency Clinical Hospital for Children 'Sf. Ioan' (Glati, Romania), with the approval no. 2774, from 18.02.2021. The guardians of the patient provided written informed consent. 


\section{Patient consent for publication}

The guardians of the patient provided consent for publication and it is included in the medical chart of the patient.

\section{Competing interests}

The authors declare that they have no competing interests.

\section{References}

1. Sehgal NV, Verma P and Chatterjee K: Type 1 neurofibromatosis (von Recklinghausen disease). Cutis 96: e23-26, 2015.

2. Leroy K, Dumas V, Martin-Garcia N, Falzone MC, Voisin MC, Wechsler J, Revuz J, Creange A, Levy E, Lantieri L, et al: Malignant peripheral nerve sheath tumors associated with neurofibromatosis type 1: A clinicopathologic and molecular study of 17 patients. Arch Dermatol 137: 908-913, 2001.

3. Feldman DS, Jordan C and Fonseca L: Orthopaedic manifestations of neurofibromatosis type 1. J Am Acad Orthop Surg 18: 346-357, 2010.

4. Hirbe AC and Gutman DH: Neurofibromatosis type 1: A multidisciplinary approach to care. Lancet Neurol 13: 834-843, 2014.

5. Ferner RE, Huson SM, Thomas N, Moss C, Willshaw H, Evans DG, Upadhyaya M, Towers R, Gleeson M, Steiger C and Kirby A: Guidelines for the diagnosis and management of individuals with neurofibromatosis 1. J Med Genet 44: 81-88, 2007.

6. Boyd KP, Korf BR and Theos A: Neurofibromatosis type 1. J Am Acad Dermatol 61: 1-14, 2009.

7. Guler M, Aydin T and Poyraz E: Neurofibromatosis type 1 with invasive spinal cord compression (case report). Afr J Pharm Pharmacol 7: 1615-1618, 2013.

8. Friedman JM: Epidemiology of neurofibromatosis type 1. Am J Med Genet 89: 1-6, 1999.

9. Lammert M, Friedman JM, Kluwe VF and Mautner VF: Prevalence of neurofibromatosis 1 in German children at elementary school enrollment. Arch Dermatol 141: 71-74, 2005.

10. Huson SM, Compston DA, Clark P and Harper PS: A genetic study of von Recklinghausen neurofibromatosis in south east Wales. Prevalence, fitness, mutaton rate and effect of parental transmision on severity. J Med Genet 26: 704-711, 1989.

11. Gutmann DH, Ferner RE, Listernick RH, Korf BR, Wolters PL and Johnson KJ: Neurofibromatosis type 1. Nat Rev Dis Primers 3: 17004, 2017.

12. Nica SC, Mihailescu G, Nica SM, Baetu C, Clatici VG and Buruga I: Neurofibromatosis-one disease for a multidisciplinary team. RoJCED 3: 38-49, 2016

13. Viskochil D, Buchberg AM, Xu G, Cawthon RM, Stevens J, Wolff RK, Culver M, Carey JC, Copeland NG and Jenkins NA: Deletions and a translocation interrupt a cloned gene at the neurofibromatosis type 1 locus. Cell 62: 187-192, 1990.

14. Li Y, O'Connell P, Breidenbach HH, Cawthon R, Stevens J, Xu G, Neil S, Robertson M, White R and Viskochil D: Genomic organization of the neurofibromatosis 1 gene (Nf1). Genomics 25: 9-18, 1995.

15. Daston MM, Scrable H, Nordlund M, Sturbaum AK, Nissen LM and Ratner N: The protein product of the neurofibromatosis type 1 gene is expressed at highest abundance in neurons, Schwann cells and oligodendrocytes. Neuron 8: 415-428, 1992.

16. Gutmann DH,ParadaLF, Silva AJand Ratner N: Neurofibromatosis type 1: Modeling CNS dysfunction. J Neurosci 32: 14087-14093, 2012.

17. Peltonen S: Neurofibromatosis type 1: Dermatologists should take an active role. Forum for Nord Derm Ven 13: 74-77, 2008.

18. Antônio JR, Goloni-Bertollo EM and Trídico LA: Neurofibromatosis: Chronological history and current issues. An Bras Dermatol 88: 329-343, 2013.

19. Stocker KM, Baizer L, Coston T, Sherman L and Ciment G: Regulated expression of neurofibromin in migrating neural crest cells of avian embryos. J Neurobiol 27: 535-552, 1995.

20. National Institutes of Health Consensus Development Conference Statement: Neurofibromatosis. Bethesda, Md., USA, July 13-15, 1987. Neurofibromatosis 1: 172-178, 1988.

21. Tonsgard JH: Clinical manifestations and management of neurofibromatosis type 1. Semin Pediatr Neurol 13: 2-7, 2006.
22. Ferner RE: Neurofibromatosis 1. Eur J Hum Genet 15: 131-138, 2007.

23. Williams VC, Lucas J, Babcock MA, Gutmann DH, Korf B and Maria BL: Neurofibromatosis type 1 revisited. Pediatrics 123: 124-133, 2009

24. Kolanczyk M, Mautner V, Kossler N, Nguyen R, Kuhnisch J, Zemojtel T, Jamsheer A, WegenerE, Thurisch B, Tinschert S, et al: MIA is a potential biomarker for tumour load in neurofibromatosis type 1. BMC Med 9: 82, 2011.

25. Tatu AL: Umbilicated blue black lesion on the lateral thorax. J Cutan Med Surg 21: 252, 2017.

26. Valeyrie-Allanore L, Ortonne $\mathrm{N}$ and Lentieri L, Ferkal S, Wechsler J, Bagot M and Wolkenstein P: Histopathologically dysplastic neurofibromas in neurofibromatosis 1: Diagnostic criteria, prevalence and clinical signifiance. Br J Dermatol 158: 1008-1012, 2008.

27. Montani D, Coulet F, Girerd B, Eyries M, Bergot E, Mal H, Biondi G, Dromer C, Hugues T, Marquette C, et al: Pulmonary hypertension in patients with neurofibromatosis type I. Medicine (Baltimore) 90: 201-211, 2011.

28. Wang J, Wei G, Wang Z and Huang H: Detection of severe hypertension in a patient with neurofibromatosis type 1 during anesthesia induction: A case report. J Med Case Rep 13: 349 , 2019.

29. Nanda A: Autoimmune diseases associated with neurofibromatosis type 1. Pediatr Dermatol 25: 392-393, 2008.

30. Tatu AL and Ionescu MA: Multiple autoimmune syndrome type III-thyroiditis, vitiligo and alopecia areata. Acta Endocrinol (Buchar) 13: 124-125, 2017.

31. Tandon S, Singh A, Arora P and Gautam RK: Neurofibromatosis with vitiligo: An uncommon association rather than coexistence? An Bras Dermatol 94: 624-626, 2019.

32. Miraglia E, Calvieri S and Giustini S: Neurofibromatosis type 1 and lichen sclerosus: An uncommon association. G Ital Dermatol Venereol 152: 83-84, 2017.

33. Mihăilă B, Dinică RM, Tatu AL and Buzia OD: New insights in vitiligo treatments using bioactive compounds from Piper nigrum. Exp Ther Med 17: 1039-1044, 2019.

34. Tatu AL and Nwabudike LC: The treatment options of male genital lichen sclerosus et atrophicus: Treatments of genital lichen sclerosus. In: Proceedings of the 14th National Congress of Urogynecology and the National Conference of the Romanian Association for the Study of Pain, pp262-264, 2017.

35. Korf BR: Diagnostic outcome in children with cafe au lait spots. Pediatrics 90: 924-927, 1992.

36. Stevenson DA, Moyer-Mileur LJ, Murray M, Slater H, Sheng X, Carey JC, Dube B and Viskochil DH: Bone mineral density in children and adolescents with neurofibromatosis type 1 . J Pediatr 150: 83-88, 2007.

37. Friedman JM and Birch PH: Type I neurofibromatosis: A descriptive analysis of the disorder in 1728 patients. Am J Med Genet 70: 138-143, 1997.

38. Gilbert A and Brockman R: Congenital pseudarthrosis of the tibia: Long-term followup of 29 cases treated by microvascularbone transfer. Clin Orthop Relat Res 314: 37-44, 1995.

39. Sulaiman AR, Nordin S, Faisham WI, Zulmi W and Halim AS: Residual nonunion following vascularized fibular graft treatment for congenital pseudarthosis of the tibia: A report of two cases. J Orthop Surg (Hong Kong) 14: 64-66, 2006.

40. Stevenson DA, Birch PH, Friedman JM, Viskochil DH, Balestrazzi P, Boni S, Buske A, Korf BR, Niimura M, Pivnick EK, et al: Descriptive analysis of tibial pseudarthrosis in patients with neurofibromatosis 1. Am J Med Genet 84: 413-419, 1999.

41. Kong LD, Cheng HX and Nie T: Treat the congenital pseudarthrosis of the tibia with Ilizarov technology. Case report. Medicine (Baltimore) 97: e13384, 2018.

42. Sakamoto A, Yoshida T, Yamamoto H, Oda Y, Tsuneyoshi M and Iwamoto Y: Congenital pseudarthrosis of the tibia: Analysis of the histology and the NF1 gene. J Orthop Sci 12: 361-365, 2007.

43. Tuncay IC, Johnston CE II and Birch JG: Spontaneous resolution of congenital anterolateral bowing of the tibia. J Pediatr Orthop 14: 599-602, 1994.

44. Crawford AH and Schorry EK: Neurofibromatosis in children: The role of the orthopaedist. J Am Acad Orthop Surg 7: 217-230, 1999.

45. Traub JA, O'Connor W and Masso PD: Congenital pseudarthrosis of the tibia: A retrospective review. J Pediatr Orthop 19: 735-738, 1999. 
46. Karol LA, Haideri NF, Halliday SE, Smitherman TB and Johnston CE II: Gait analysis and muscle strength in children with congenital pseudarthrosis of the tibia: The effect of treatment. J Pediatr Orthop 18: 381-386, 1998.

47. Vanderstappen J, Lammens J, Berger P and Laumen A: Ilizarov bone transplant as a treatment of congenital pseudarthrosis of the tibia: A long-term follow-up study. J Child Orthop 9: 319-324, 2015.

48. Ippolito E, Corsi A, Grill F, Wientroub S and Bianco P: Pathology of bone lesions associated with congenital pseudarthrosis of the leg. J Pediatr Orthop B 9: 3-10, 2000.

49. Hefti F, Bollini C, Dungl P, Fixsen J, Grill F, Ippolito E, Romanus B, Tudisco C and Wientroub S: Congenital pseudarthrosis of the tibia: History, etiology, classification and epideiologic data. J Pediatr Orthop B 9: 11-15, 2000.

50. Lehman WB, Atar D, Feldman DS, Gordon JC and Grant AD: Congenital pseudarthrosis of the tibia. J Pediatr Orthop B 9: 103-107, 2000.

51. Tudisco C, Bollini C, Dungel P, Fixen J, Grill F, Hefti F, Romanus B and Wientroub S: Functional results at the end of skeletal growth in 30 patients affected by congenital pseudarthrosis of the tibia. J Pediatr Orthop B 9: 94-102, 2000.

52. Grill F, Bollini C, Dungl P, Fixsen J, Hefti F, Ippolito E, Romanus B, Tudisco C and Wientroub S: Treatment approaches for congenital psedarthrosis of tibia: Results of the EPOS multicenter study. European Paediatric Orthopaedic Society (EPOS). J Pediatr Orthop B 9: 75-89, 2000

53. Elefteriou F, Kolnczyk M, Schindeler A, Viskochil DH, Hock JM, Schorry EK, Crawford AH, Friedman JM,Little D, Peltonen J, et al: Skeletal abnormalities in neurofibromatosis type 1: Approaches to therapeutic options. Am J Med Genet A 149A: 2327-2338, 2009.

54. Dobbs MB, Rich MM, Gordon JE, Szymanski DA and Schoenecker PL: Use of an intramedullary rod for treatment of congenital pseudarthrosis of the tibia: A long-term follow-up study. J Bone Joint Surg Am 86: 1186-1197, 2004.
55. Boero S, Catagni M, Donzelli O, Facchini R and Frediani PV: Congenital pseudarthrosis of the tibia associated with neurofibromatosis 1: Treatment with Ilizarov's device. J Pediatr Orthop 17: 675-684, 1997.

56. Velan CJ, Katz K and Hendel D: Failed treatment of congenital pseudarthrosis of the tibia-a case of Ilizarov transportation of proximal tibia with artrodesis to talus. Acta Orthop Scand 69: 433-434, 1998

57. Ramachandran M, Tsirikos AI, Lee J and Saifuddin A: Whole-spine magnetic resonance imaging in patients with neurofibromatosis type 1 and spinal deformity. J Spinal Disord Tech 17: 483-491, 2004.

58. Singh K, Samartzis D and An HS: Neurofibromatosis type 1 with severe dystrophic kyphoscoliosis and its operative management via a simultaneous anterior-posterior approach: A case report and review of the literature. Spine J 5: 461-466, 2005.

59. Li M, Fang X, Li Y, Ni J, Gu S and Zhu X: Succesful use of posterior instrumented spinal fusion alone for scoliosis in 19 patients with neurofibromatosis type-1 followed up for at least 25 months. Arch Orthop Trauma Surg 129: 915-921, 2009.

60. Ardeleanu V, Chicoş SC, Tutunaru D and Georgescu C: Multiple benign symmetric lipomatosis-a differential diagnosis of obesity. Chirurgia (Bucur) 108: 580-583, 2013.

61. Ardeleanu V, Toma A, Pafili K, Papanas N, Motofei I, Diaconu CC, Rizzo M and Stoian AP: Current pharmacological treatment of painful diabetic neuropathy: A narrative review. Medicina (Kaunas) 56: 25, 2020 International (CC BY-NC-ND 4.0) License. 